\title{
O Cinema Como Criador de Tendências e Fonte de Pesquisa Histórica na Moda
}

Maria Paula Guimarães

Mestranda, Escola de Design Universidade Estadual de Minas Gerais / mariapauladesigndemoda@gmail.com Orcid: 0000-0002-5264-1139/lattes

Rita Aparecida da Conceição Ribeiro

Doutora, Escola de Design Universidade Estadual de Minas / rribeiroed@gmail.com Orcid: 0000-0003-0748-854X/lattes 


\title{
O Cinema Como Criador de Tendências e Fonte de Pesquisa Histórica na Moda
}

\begin{abstract}
RESUMO
Apesar de ter surgido na Europa em fins do século XIX, foi nos Estados Unidos que o cinema teve seu maior desenvolvimento e consolidou-se como uma atividade de produção multidisciplinar e seus múltiplos estilos e gêneros tornaram-se objeto de vários estudos. A correta interpretação dos conteúdos simbólicos do projeto fílmico possibilita um entendimento das condições socioeconômicas de uma época tornando-se então uma importante fonte de pesquisa histórica. Este artigo propõe uma classificação dos figurinos de cinema, trazendo um novo olhar para 0 entendimento de filmes que reconstituem outras épocas, ampliando assim a classificação criada por Betton (1987). Para este artigo foram analisados três filmes do gênero musical, considerando uma linha de pesquisa sobre a influência exercida pelo cinema na construção de tendências da cultura jovem onde a música constitui um vetor central. Os filmes analisados são: Amor, Sublime Amor (1961), Os Embalos de Sábado à noite (1977) e Hair (1978), classificados nas categorias de reconstituição de época, figurino contemporâneo e livre interpretação de época, possibilitando a identificação mais objetiva dos laços existentes entre a realidade socioeconômica de cada época e o cinema, interferindo na constituição de hábitos e costumes de um grupo social.
\end{abstract}

Palavras-chave: moda; cinema; figurino. 


\title{
Cinema as a Trendsetter and Source of Historical Research in Fashion
}

\begin{abstract}
Although it emerged in Europe in the late nineteenth century, it was in the United States that cinema had its greatest development and consolidated as a multidisciplinary production activity and its multiple styles and genres became the subject of several studies. The correct interpretation of the symbolic contents of the film project enables an understanding of the socioeconomic conditions of an era and then becomes an important source of historical research. This article proposes a classification of cinema costumes, bringing a new look to the understanding of films that reconstitute other epochs, thus broadening the classification created by Betton (1987). For this article, three films of the musical genre were analyzed, considering a line of research on the influence exerted by the cinema in the construction of tendencies of the young culture where the music constitutes a central vector. The films analyzed are: Amor, Sublime Amor (1961), The Saturday Night Fever (1977) and Hair (1978), classified in the categories of period reconstruction, contemporary costumes and free interpretation of the time, allowing a more objective identification of ties between the socioeconomic reality of each era and the cinema, interfering in the constitution of habits and customs of a social group.
\end{abstract}

Keywords: fashion; cinema; history. 


\section{INTRODUÇÃO}

Desde seu surgimento (1895), pelas mãos dos irmãos Lumière, o cinema é responsável por encantar gerações (SOUZA, 2005). Concebido como instrumento de registro da realidade, logo se transformou em entretenimento graças ao trabalho do mágico e ilusionista Georges Méliès (18611938), que revelou as inúmeras possibilidades de manipulação da imagem e concebeu o cinema como espetáculo. Seu desenvolvimento rápido foi fruto de uma sociedade ávida por entretenimento e foi nos Estados Unidos que se deu seu maior impulso. Inicialmente, o cinema mudo, contava com acompanhamento musical e, muitas vezes, narração do enredo, ao vivo, dentro das salas de exibição.

Ainda de acordo com Souza (2005), a introdução do cinema falado, ou seja, com trilha sonora gravada e sincronizada, em 1927 com o filme "O Cantor de Jazz", provocou uma mudança substancial no processo de produção dos filmes. A concepção de um filme passa a se desenvolver como um projeto multidisciplinar, envolvendo diversos profissionais de áreas distintas com intuito de ser o mais fiel possível a um enredo determinado, geralmente orquestrado por um diretor ou produtor capaz de promover a perfeita integração das diversas áreas.

No decorrer do século $X X$ vários estilos de filmes foram surgindo, novas formas de filmar, de produzir, de construir enredos. Betton (1987) explica que são classificados por gêneros, aqueles filmes que se enquadram a certas características definidas do enredo tais como drama, comédia, aventura, ficção científica e muitos outros. Por outro lado, a forma de se fazer os filmes pode diferenciá-los e várias correntes apareceram como os filmes "noir", a "nouvelle vague" francesa, o cinema alemão e outras 
correntes estilísticas, compondo uma linguagem cinematográfica rica e bem definida.

O cinema é, antes de mais nada, uma arte, um espetáculo artístico. É também uma linguagem estética, poética ou musical - com uma sintaxe e um estilo; é uma escrita figurativa, e ainda uma leitura, um meio de comunicar pensamentos, veicular ideias e exprimir sentimentos. Uma forma de expressão tão ampla quanto as outras linguagens (literatura, teatro, etc.), bastante elaborada e específica. Fazer um filme é organizar uma série de elementos espetaculares a fim de proporcionar uma visão estética, objetiva, subjetiva ou poética do mundo[...] (BETTON, 1987).

Além de espetáculo e entretenimento, o cinema também pode ser considerado uma fonte histórica. De acordo com Marc Ferro (1992), o cinema é agente e fonte da história. O cinema se baseia nos acontecimentos para criar suas ações. Não só pela produção de cinema documentário, que registrou muitos momentos históricos importantes, 0 cinema, mesmo, em sua fantasia, retrata uma realidade, ou se permeia pela realidade que se vive quando da produção do filme. Marc Ferro, em seu livro "Cinema e História" destaca o papel do cinema como fonte histórica que deve ser reconhecida pelos historiadores.

O filme, aqui, não está sendo considerado do ponto de vista semiológico. Também não se trata de estética ou de história do cinema. Ele está sendo observado não como uma obra de arte, mas sim como um produto, uma imagem-objeto, cuja significações não são somente cinematográficas. Ele não vale somente por aquilo que testemunha, mas também pela abordagem sócio histórica que autoriza. A análise não incide necessariamente sobre a obra em sua totalidade: ela pode se apoiar sobre estratos, pesquisar "séries", compor conjuntos. E a crítica também não se limita ao filme, ela se integra ao mundo que o rodeia e com o qual se comunica, necessariamente. Nessas condições, não seria suficiente empreender análise de filmes, de trechos de filmes, de planos, de temas, levando em conta, segundo a necessidade, o saber e a abordagem das diferentes ciências humanas. É preciso aplicar esses métodos a cada um dos substratos do filme (imagens, imagens sonorizadas, não sonorizadas) as relações entre os componentes desses substratos; 
analisar no filme tanto a narrativa quanto o cenário, a escritura, as relações do filme com aquilo que não é o filme: o autor, a produção, o público, a crítica, o regime do governo. Só assim se pode chegara compreensão não apenas da obra, mas também da realidade que ela representa. (FERRO, 1992).

Desta forma, o filme pode ser visto de diversas maneiras, como entretenimento ou como objeto simbólico, no qual diversos signos podem ser decodificados na busca do entendimento de um conteúdo subjetivo, que pode ser intencional ou não. Ainda, o filme pode ser analisado de forma a proporcionar um entendimento das condições sócio culturais de uma determinada época através de uma análise reflexiva concernente ao momento histórico de sua produção, tornando-se um importante referencial de seu tempo.

Assim, o objetivo deste artigo é identificar a possibilidade de se considerar o filme como fonte de pesquisa histórica, através da análise de seus figurinos; sendo estes classificados em categorias, possibilitando a correta interpretação dos conteúdos simbólicos das roupas e sua identificação dentro do contexto histórico a que se referem. Para exemplificar, foram escolhidos três filmes musicais, com uma temática em comum que serão interpretados de acordo com a classificação proposta. Para serem analisados neste artigo, foram escolhidos três filmes musicais, cuja temática está relacionada aos questionamentos da juventude, e que, através da trilha sonora e figurinos, marcaram época: 1) Amor, Sublime Amor (1961); 2) Hair (1979); 3) Os Embalos de Sábado à Noite (1977). (Figura 1) 
Figura 1: Cartazes dos filmes Amor Sublime Amor, Hair e Os Embalos de Sábado à Noite.
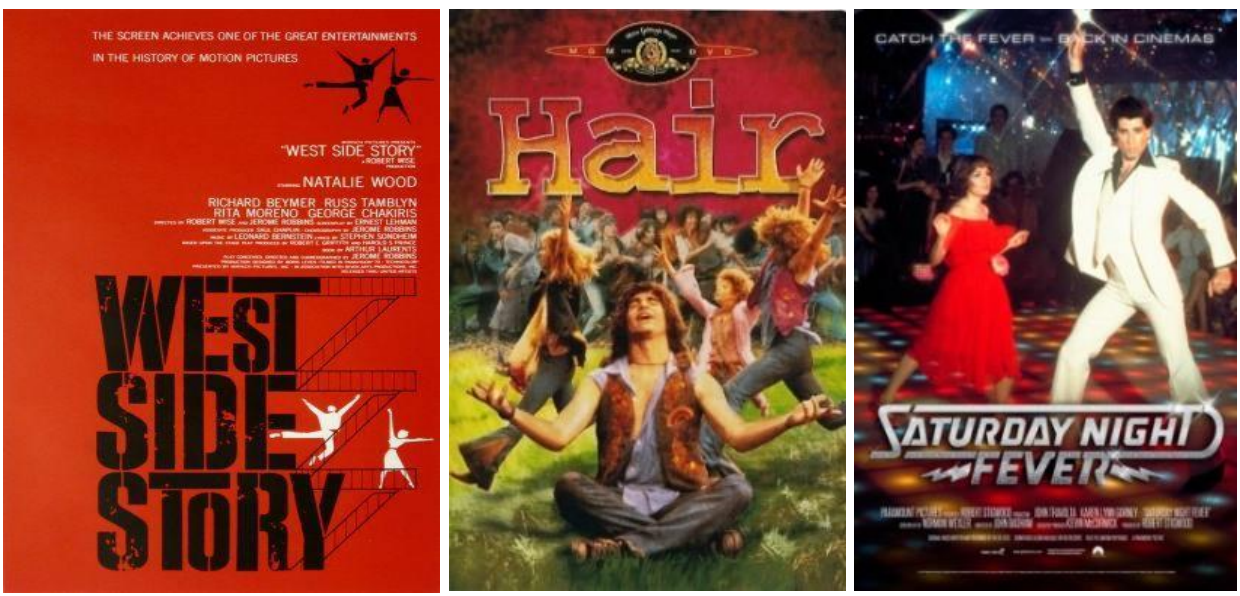

Fonte: http://www.adorocinema.com/filmes/filme-208/

\section{O RESSURGIMENTO DO FILME MUSICALNA DÉCADA DE 1960-1970}

Filme Musical é uma classificação abrangente para filmes que tenham a narrativa conduzida por canções. Segundo Souza; et al. (2011), "filme musical é um gênero de filme, no qual a narrativa se apoia sobre uma sequência de músicas coreografadas, utilizando música, canções e coreografia como forma de narrativa, predominante ou exclusivamente". O filme musical, também pode ser um drama, uma comédia, terror, western, etc., e, apesar de rotulado como um gênero escapista e alienante, seu enorme sucesso, desde o cinema falado, arrebatou grandes êxitos de público e crítica na história do cinema hollywoodiano. Segundo Souza (2005), o estilo musical de filmes teve sua época de ouro nas décadas entre 1930 e 1950, quando o cinema era a forma mais importante de entretenimento popular.

Nas décadas seguintes, 1960 e 1970, ainda de acordo com Souza (2005), "Já nos anos 1960 com a decadência do sistema de estúdio e o crescimento da televisão, os musicais entraram em decadência nos Estados Unidos". Quando o 
sucesso dos filmes musicais não estava mais tão evidente, novas temáticas foram introduzidas como forma de atração de público.

A explosão dos" Baby Boomers" ${ }^{1}$, adolescentes e jovens consumidores demandavam um novo mercado que iria de objetos, roupas e acessórios, e principalmente entretenimento. Para atender este novo padrão de consumo, os temas relacionados com os conflitos da juventude e as influências de correntes musicais diversas ligadas aos jovens proporcionaram uma nova perspectiva temática aos estúdios de cinema (SOUZA, 2005). Outro tema importante da época foi os ligados aos bastidores do mundo musical, assim como uma pluralidade de abordagens e experimentações, responsáveis por sucessos que ressuscitaram e fortaleceram o estilo musical. Diretores e roteiristas renomados envolveram-se nas produções, bem como coreógrafos, compositores, músicos e bandas já consagrados, o que lhes rendeu muitos prêmios.

Algumas produções de filmes musicais foram direcionadas para o público jovem, abordando uma temática relacionada aos problemas e conflitos juvenis. As trilhas sonoras dos musicais, combinadas com as coreografias, fizeram de alguns filmes referência da cultura jovem de sua época. Por conseguinte, os figurinos apresentados mostraram uma influência significativa na moda, quando eram admirados e imitados pelos jovens. Segundo Lipovetsky (2015), as identidades juvenis são constituídas pela apropriação de objetos, roupas e modelos apresentados muitas vezes pelos astros de cinema e cantores preferidos, neste caso o design deve privilegiar os gostos e preferências

\footnotetext{
1 Baby Boomers é a geração dos nascidos após Segunda Guerra Mundial até a metade da década de 1960. A designação vem da expressão "baby boom", que representa a explosão na taxa de natalidade nos Estados Unidos no pós-guerra e que constituíram um importante mercado consumidor devido com um poder aquisitivo e demandas de um mercado jovem. Fonte: dicionário financeiro, disponível em https://www.dicionariofinanceiro.com/baby-boomers/. Acesso em 27 jun. 2018
} 
desta juventude, como forma de aproximação deste mercado consumidor.

\section{CLASSIFICAÇÃO DE FIGURINO DE CINEMA}

A leitura global do figurino caracteriza-se por uma série de premissas formais e culturais do discurso cinematográfico, sem esquecer os gestos do corpo e a sua ligação à moda e suas idiossincrasias, principalmente aquelas que conseguem envolver o espectador na narrativa, pelo fato de the serem familiares e equivalerem a situações semelhantes às do seu quotidiano e contexto cultural. $O$ figurino, então, reflete muitas vezes os hábitos e costumes da sociedade a qual o projeto fílmico se refere, valendo-se como fonte para pesquisa de hábitos e costumes de uma sociedade ali identificada, através da correta interpretação simbólica e de suas idiossincrasias. Para a decodificação do figurino de filme como elemento de identificação do papel socioeconômico retratado na produção, faz-se necessário estabelecer uma classificação, para identificarmos seus laços com a realidade e o que tem de relação com a complexidade e composição do personagem.

Gerard Betton, em seu livro A Estética do Cinema (1987), faz a seguinte classificação dos figurinos de cinema: 1)Figurinos realistas, comportando todos os figurinos que retratam o vestuário da época representado pelo filme com precisão histórica, 2) para-realistas, quando o figurinista se inspira na moda da época para realizar o seu trabalho, mas procedendo de estilização, onde a preocupação com estilo e a beleza prevalece sobre a exatidão pura e simples e 3) simbólicos, quando a exatidão histórica perde completamente a importância e cede espaço para a função de traduzir simbolicamente caráteres, estados de alma, ou ainda, de criar efeitos dramáticos ou psicológicos 
Na análise de Betton (1987), não fica claro como se classificam os figurinos dos filmes que retratam outra época diferente da época de sua produção. Com a finalidade de analisar os filmes na forma em que se inserem em uma linha cronológica, o que se faz bastante relevante quando se tem o olhar do design de moda, este artigo propõe uma nova classificação dos figurinos, que são as seguintes: a) reconstituição de época, b) figurino contemporâneo e c) livre interpretação de época, e que, de modo geral, os projetos filmicos podem ser divididos dentro destas três categorias.

A) RECONSTITUIÇÃO DE ÉPOCA

A reconstituição de época tem sido uma das grandes fontes de divulgação de pesquisas de vestuário desde o início do cinema, para Marc Ferro "o cinema é um testemunho singular de seu tempo, pois está fora do controle de qualquer instância de produção, principalmente o Estado. Mesmo a censura não consegue dominá-lo". Outros historiadores também debateram o assunto como o alemão Kracauer (1947) em Kornis (1992) "considerava que os filmes de ficção refletiam de forma imediata a mentalidade de uma nação, estabelecendo assim uma relação direta entre o filme e o meio que o produz". De posse de facilidade de recursos, ao longo de sua história, a indústria cinematográfica hollywoodiana, não tem medido esforços para reconstrução de outras épocas de forma mais autêntica possível. Nesta classificação, a verossimilhança deve ser a mais próxima da realidade, dentro das possibilidades fornecidas pelos materiais disponíveis. A pesquisa em todo 0 tipo de material oferece, muitas vezes, a forma de confecção utilizada, bem como os outros materiais empregados, padrão de cores, etc., produzindo um rico acervo de roupas, acessórios, joias, penteados, maquiagens e cenografia utilizada na produção da obra. 
Não obstante, não podemos esquecer a temporalidade da produção, que muitas vezes impõe certos aspectos estéticos relativos à época da realização do filme, indiferentemente da realidade a ser retratada. Muitas vezes, podemos perceber nos filmes bíblicos e épicos produzidos na década de 1940, tipos de corte nas vestimentas femininas bem como o penteado e a maquiagem, característicos da moda vigente na época de produção do filme. É o caso do filme Sansão e Dalila (1949), conforme mostra a figura 2. O vestido exibe as características marcantes da moda do momento da filmagem, bordados e maquiagem que não faziam parte do universo estético da época retratada no filme.

Figura 2: Cena do filme "Sansão e Dalila" (1949).

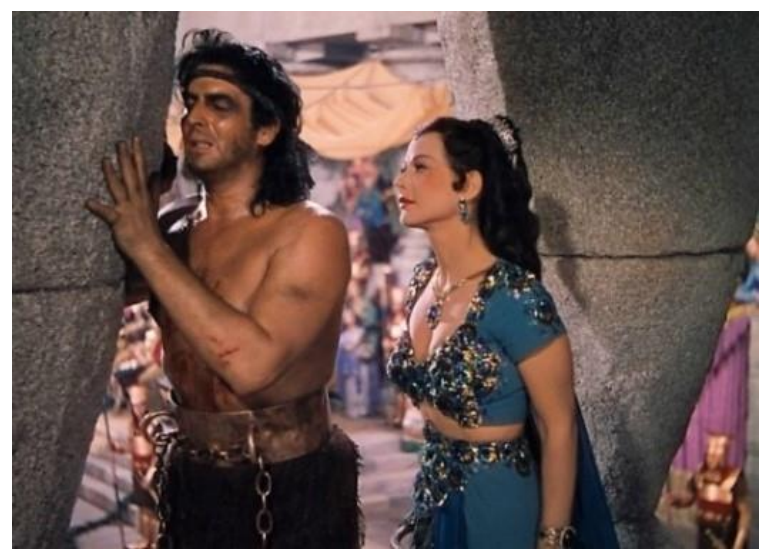

Fonte: https://3.bp.blogspot.com/-T1Ib_gDbyw/V9nAeaCi3VI/AAAAAAAAUN8/Eoxwp 7xsCcUzjN_4 foBkfVoEtj140jzqACLcB/s640/sa msonanddelilah-blu ray-

07.jpg

Em Cleópatra (1963), apesar do figurino classificado como "estonteante" por muitos críticos de cinema, considerado um atrativo a mais do filme, os vestidos da atriz Elizabeth Taylor, mostram claramente a influência da moda da época da produção do filme, nos anos de 1960, como mostra o exemplo da figura 3 . O vestido verde usado pela atriz poderia ser usado em qualquer ocasião fora das telas. A estrutura de modelagem do vestido marrom também mostra claramente o estilo de modelagem vigente nos anos 1960, com os seios bem definidos. 
Figura 3: Cenas do filme "Cleópatra" (1963).

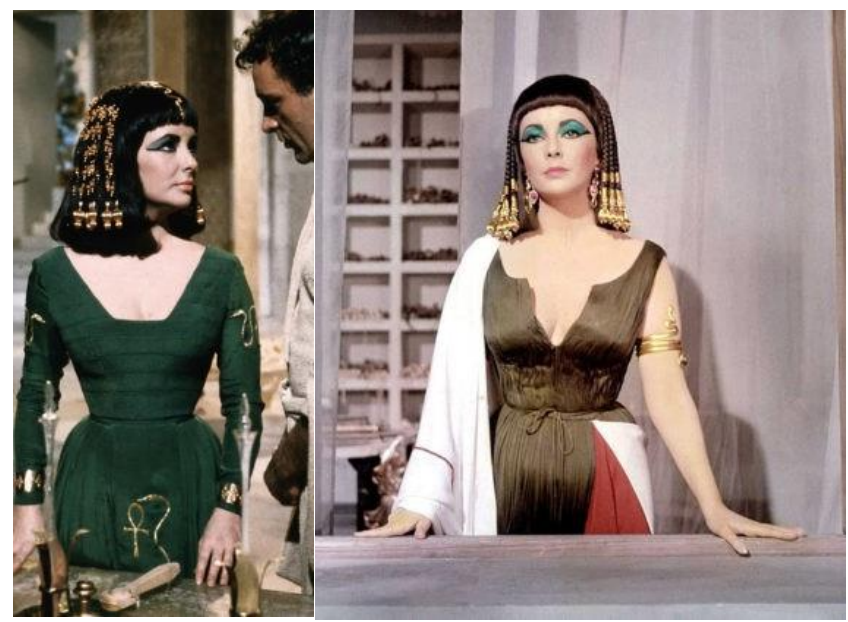

Fonte: http://cinemaclassico.com/wpcontent/uploads/2017/04/2elizabeth3-206x420.jpg; http://cinemaclassico.com/wpcontent/uploads/2017/04/1elizabeth10-362x420.jpg

Em projetos mais recentes a preocupação com a verossimilhança vem se mostrando cada vez mais forte e os filmes são verdadeiros estudos em termos de vestuário, costumes e cenografia. Um exemplo importante é o filme "A Paixão de Cristo" (2004) com Mel Gibson, que além da preocupação com a língua, falado em aramaico, traz um figurino impecável, em se tratando dos materiais utilizados, formas e modelagens, acessórios, e outros aspectos cenográficos. Na figura 4 , observa-se a textura dos tecidos e o detalhe da sandália.

Figura 4: Cena do filme "A paixão de Cristo" (2004).

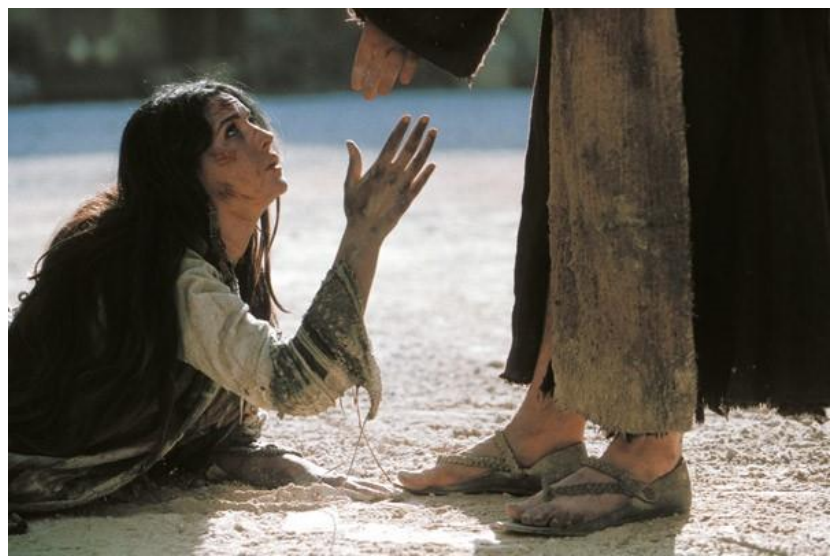

Fonte: http://br.web.img3.acsta.net/r_1920_1080/ medias/nmedia/18/35/22/44/18375164.jpg 
Algumas séries produzidas para a TV, também se têm mostrado obras valiosas na reconstituição de época, pelo aprimoramento do figurino e cenografia, como o caso da série "DowntonAbbey" (2010), com peças que mostram até os formatos de corte de cavas e golas, abotoamentos dos casacos, casas de botões feitas à mão e muitos outros detalhes extremamente autênticos, conseguindo transportar para a tela uma atmosfera de tempos passados.

O figurino muitas vezes, serve como elemento para identificar o personagem e separá-lo da persona do autor que o interpreta, além de separá-lo de outros tipos e personagens da galeria de interpretações do ator. Atores famosos têm presença constante na mídia, e se tornam familiares para a plateia - para fazê-los parecerem pessoas diferentes daquelas vistas em noticiário e colunas sociais, seus personagens devem parecer diferentes na tela de cinema. Neste ponto entra - figurino criando elementos próprios para cada personagem. (COSTA, 2002)

Desta forma, aliado à cenografia, o figurino faz uma ponte com o passado, tornando a experiência vivida pelo expectador bastante autêntica.

B) FIGURINO CONTEMPORÂNEO

A tarefa de caracterização de um personagem na produção de um filme passa, além é claro da interpretação do ator, pelos elementos que compõem sua imagem. Podemos então falar de figurino, que inclui roupas e acessórios, maquiagem e cabelo. Este universo contribui para que 0 ator adquira o clima necessário para sua interpretação e o figurino assume um caráter de comunicação.

No caso da produção de figurino contemporâneo, além da época da produção do filme, alguns elementos devem ser levados em conta pelo figurinista, para que o resultado atinja o objetivo dentro do enredo. Deve-se considerar a 
posição social e econômica da personagem, os traços de personalidade e a vida interior das personagens que habitam o mundo ficcional. $O$ vestuário detém uma ligação estreita com a caracterização psicológica das personagens, sua ligação e hierarquia em relação às outras, sua contextualização no espaço de ação, em que se desenrolam as cenas definindo-o. As relações hierárquicas entre personagens são evidentes através do uso do vestuário, por comparação dos tipos de roupa, adereços, caracterização, gestos, atitudes e cenários, sendo que estes últimos em muito contribuem na caracterização das personagens, porque "oferecem ou sugerem o fundo adequado para a ação" (Carpinteira, 2011).

Para criar a ligação e envolvimento entre espectador e personagem, peças do vestuário do quotidiano do público precisam ser introduzidas no figurino e cenografia, criando elos de emoção com o personagem e envolvimento na trama. Neste momento, podemos fazer a ligação entre cinema e moda, pois o figurinista toma para si a responsabilidade de introduzir determinados itens do vestuário que irão influenciar a vida quotidiana das pessoas.

Partimos agora para a relação entre a moda e o cinema, ambos são vendedores de representações, de sonhos e fantasias. Então o cinema deixa de ser apenas uma referência de moda e comportamento e passa agora a ser também uma indústria vendedora de moda.

Essa relação moda/cinema não é atual, vem, especialmente, das décadas de 30, 40 e 50 quando não havia a televisão e ele reinava absoluto. Não somente os figurinos eram copiados, mas também a atitude dos atores, o modo de fumar, sentar e andar era imitada. Direto das "telonas", as cenas eram divulgadas via imprensa, por revistas para o público que pagava para saber como viviam seus artistas prediletos. (BATTISTI, 2009) 
Desta forma, a interligação do sistema de moda e o cinema vêm se tornando presente desde as primeiras décadas do cinema hollywoodiano. Alguns renomados figurinistas fizeram parcerias com grandes nomes da altacostura para a construção do figurino de seus personagens. Como foi o caso do figurino do filme "Um Corpo que Cai" (1958) de Alfred Hitchcock. A protagonista, interpretada pela atriz Kim Novack (1933-), vivia duas personagens dentro da trama, assim sendo, para que o espectador as distinguisse, o figurino tornou-se parte fundamental da trama. Uma das personagens é uma moça de origem simples e vulgar, já a outra, uma moça rica, de sociedade, que para se destacar em um dos principais momentos do filme veste um costume do costureiro Hubert de Givenchy (1927-2018), grande estilista francês que vestiu muitas atrizes em Hollywood, diferenciando a personagem com classe e elegância. (Figura 5)

Figura 5: A atriz Kim Novack e suas duas personagens no filme Um Corpo que Cai (1958).

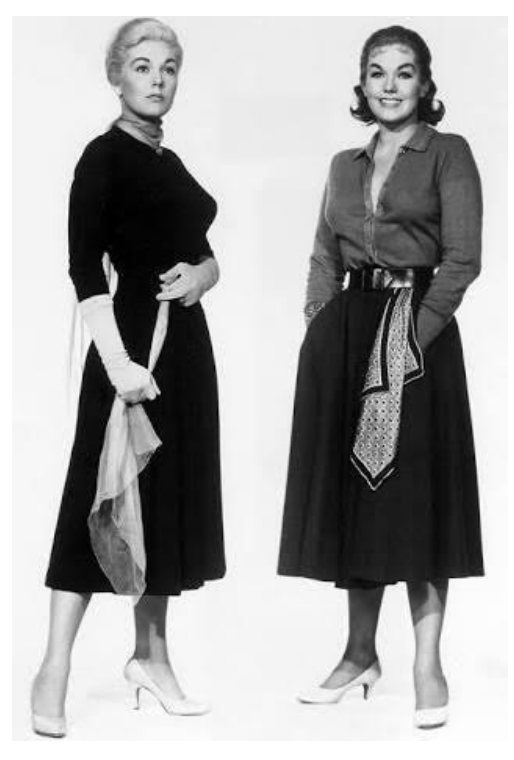

Fonte:

http://68. media.tumblr.com/e2b238f 1f2a9bcb7eab05c 7 a61ed6901/tumblr_n6c79jw6i01sw9yuuo1_500.png

Outros filmes contemporâneos que se destacam na interligação de figurino/moda, são "O Diabo Veste Prada" 
(2007) e os dois filmes da série "Sex in The City" (2008 a 2010). É importante notar que nestes três filmes o figurino faz parte da trama do enredo, quase como se fosse um personagem extra que se destaca e se faz presente em todo o filme. Nestas obras os figurinos foram cuidadosamente construídos para cada personagem, além de mostrarem verdadeiras coleções da alta costura internacional, influenciando o cenário da moda da época.

C) LIVRE INTERPRETAÇÃO DE ÉPOCA

Muitos filmes, embora retratem uma época histórica específica, priorizam diversas vezes aspectos dramáticos e psicológicos em detrimento dos aspectos da fidelidade temporal. São filmes que, apesar do figurino e cenografia inserir o espectador em um tempo e espaço específico, um contexto histórico, proporciona uma atmosfera menos real, mais manipulável e atemporal. Escolhe a estilização que prevalece sobre a precisão. Podemos exemplificar com o filme "Maria Antonieta" (2007), onde ainda que haja precisão em relação ao momento histórico do filme, existiu uma atmosfera intencionalmente fantasiosa, proporcionada muitas vezes por um exagero na composição do figurino.

Filmes cuja temática seja o futuro sempre estarão inseridos nesta classificação. Porém, muitas vezes, se referenciam ou se inspiram no passado. Como é o caso de "Blade Runner, O Caçador de Androides" (1982), onde o figurino do personagem principal, o detetive vivido pelo ator Harrison Ford na cidade de Los Angeles de 2023, foi inspirado pelo figurino de outro detetive, mas da década de 1940, vivido pelo ator Humphrey Bogart. Outro exemplo de filme futurista, que utiliza a livre interpretação de época, é o filme "Barbarella" (1968), passado no século XXXI e, lançado no auge da "era espacial" ${ }^{2}$, um ano antes de o homem pisar

\footnotetext{
${ }^{2}$ Considera-se era espacial período iniciado em 1957 com o lançamento do Sputnik, primeiro satélite artificial. As duas superpotências da época, Estados Unidos e União Soviética disputavam a supremacia tecnológica e científica que supostamente refletiria a superioridade de um sistema político-econômico. No design, as linhas
} 
na lua. O figurino tentava retratar o futuro, porém foi produzido por um estilista renomado da época, Paco Rabane, figura 6. Não podemos saber ao certo se o filme, com seu sucesso de bilheteria, influenciou a moda da época, ou a moda da época encontrou espaço dentro do filme.

Figura 6: Figurino do filme "Barbarella" (1968).

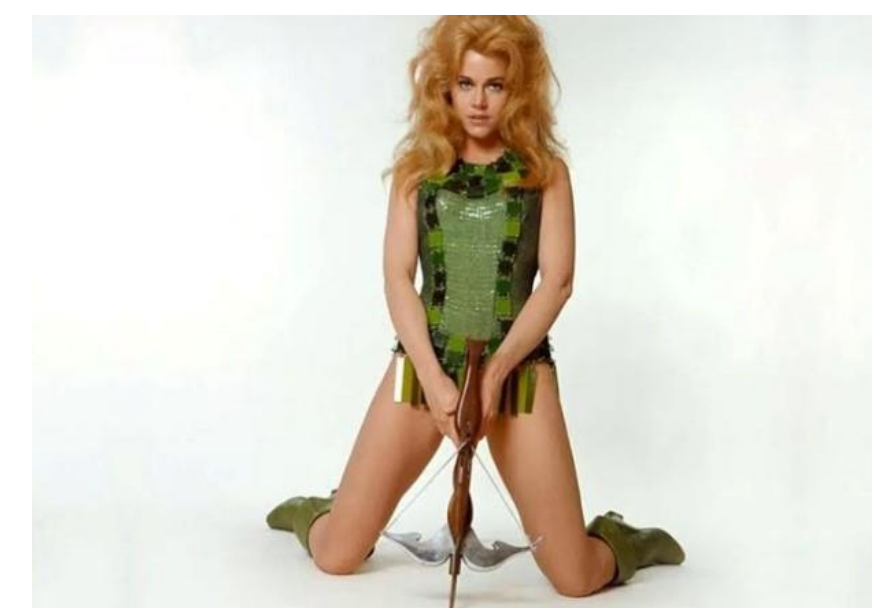

Fonte: http://universoretro.com.br/wpcontent/uploads/2016/03/barbarella-figurino.jpg

Desta forma, podemos entender que não existe uma classificação rígida e excludente em ralação ao figurino de cinema. Apenas tomamos por base, certos parâmetros como metodologia de pesquisa.

\section{ANÁLISE DAS OBRAS}

A análise destas obras tem como objetivo exemplificar a classificação proposta e contextualizar nos filmes, a relação moda, cinema e a sociedade de cada época.

Em Amor Sublime Amor, dirigido por Robert Wise (1961), inspirado em um musical homônimo da Broadway, é abordada a temática dos imigrantes porto-riquenhos em Nova York e a rivalidade das gangues formadas por grupos

arrojadas das novas formas espaciais se fizeram presentes, muitas vezes influenciaram a moda, decoração, artes gráficas, etc. Fonte: Portal do Astrônomo, disponível em

http://vintage.portaldoastronomo.org/cronica.php?id=82. Acesso em 27 jun. 2018 
de nova-iorquinos, os "Jets" e o grupo de porto-riquenhos, os "Sharks". Toda a trama gira em volta do romance proibido da garota Maria, porto-riquenha, e do estadunidense Tony. O enredo é claramente uma alusão ao romance shakespeariano "Romeu e Julieta (o amor proibido pela rivalidade de dois grupos), terminando tragicamente com a separação do casal pela morte do personagem Tony. "A coreografia integra as canções ao enredo do filme e não existem separações entre a ação dramática e as sequências musicais, o que foi inovador para a época" (SOUZA, 2005).

O figurino do filme, passado em um momento contemporâneo da produção, de autoria da figurinista Irene Sharaff (1910-1983), preocupa-se em fornecer identidade às duas gangues rivais. Desta forma, os figurinos, que precisavam se adaptar aos números de dança eram compostos de roupas da moda da época, sendo a identidade conferida através da utilização das cores. Para os portoriquenhos as cores utilizadas para as roupas eram em geral o vermelho, o preto, marrons e tons terrosos como mostra a figura 7. Já nos trajes dos americanos foram utilizadas cores mais claras e pastéis, como verdes, azuis e amarelos, figura 8. Desta forma o figurino passa ter um caráter de diferenciação dentro do contexto do filme.

Figura 7: Os tons terrosos e iluminação reforçam o figurino dos porto-riquenhos na coreografia.

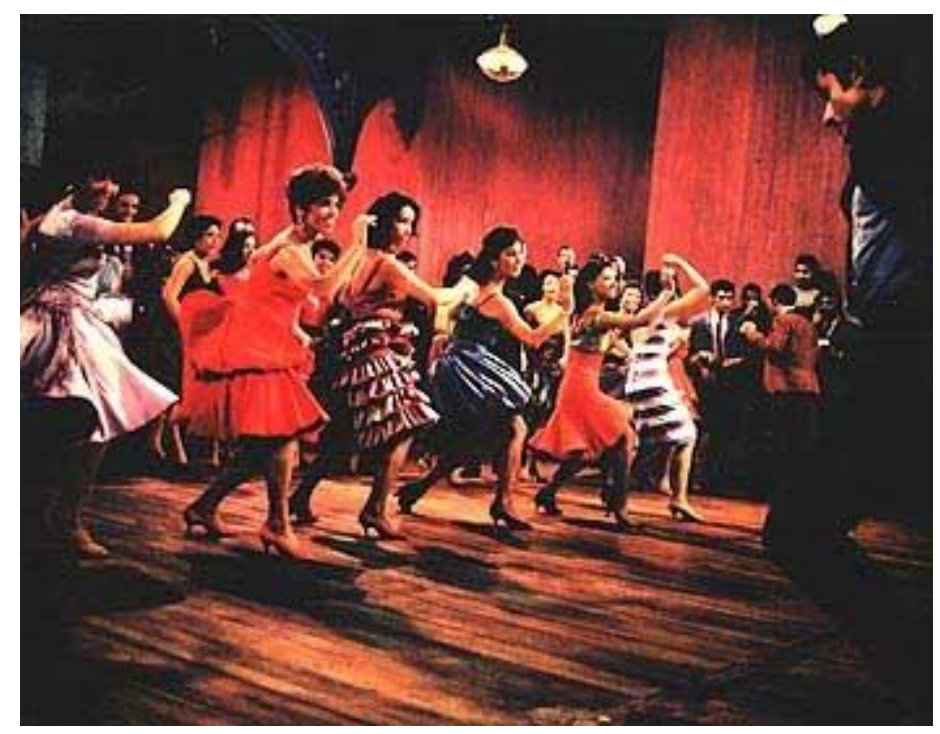


Figura 8: As cores como elemento de diferenciação entre as gangues no filme Amor, Sublime.

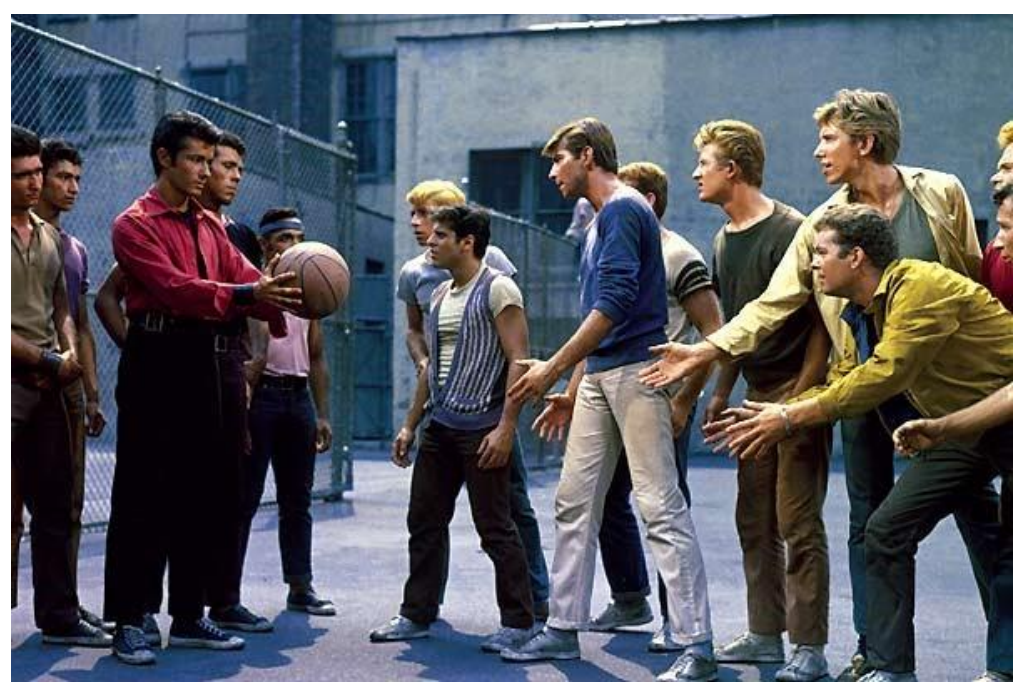

Fonte: http://br.web.img3.acsta.net/r_1920_1080/ pictures/17/03/23/10/26/179759.jpg

Em "Hair", dirigido por Milos Forman (1978), outros temas concernentes à juventude foram abordados: o movimento Hippie, as drogas e a Guerra do Vietnã. Nesta produção, inspirada no musical homônimo da Broadway, música e coreografia também se fundem com o enredo do filme de forma extremamente bem-sucedida, envolvendo o público.

Associar o movimento hippie à música era uma solução óbvia, mas que garantiu ao filme realizar suas sequências musicais sem fugir da realidade. A loucura e a liberdade de expressão, normalmente associadas aos hippies, permitiam que os personagens saíssem cantando e dançando pelas ruas sem que isso fosse considerado irreal. As fantasias e alucinações eram justificadas pelo uso de drogas (...) (SOUZA, 2005).

O figurino, produzido pela figurinista Ann Roth (1931-), foi uma reconstituição de época, apesar da pouca distância cronológica. A ideologia hippie foi transposta para o filme através da composição do figurino do núcleo dos personagens hippies, por meio de uma indumentária 
enfeitada e colorida com calças de boca de sino, blusas floridas, batas, estampas florais e étnicas, franjas, artigos em couro, flores nos cabelos, xales estampados, cabelos à moda "blackpower", longos e desalinhados, em um clima de liberdade, bem próprio desta cultura. Já a protagonista, que não pertencia ao grupo, vestia-se de maneira clássica, com acessórios elegantes, mesmo sendo jovem, demonstrando claramente a classe social a qual pertencia. Dois momentos destacam-se em relação ao figurino, o de uma festa na casa da protagonista, figura 9, na qual ela e suas amigas recebiam os convidados com roupas elegantes e bem joviais em tons claros, mostrando a posição de jovens debutantes.

Figura 9: Cena de uma festa que mostra a formalidade e a forma juvenil da atriz principal e suas amigas.

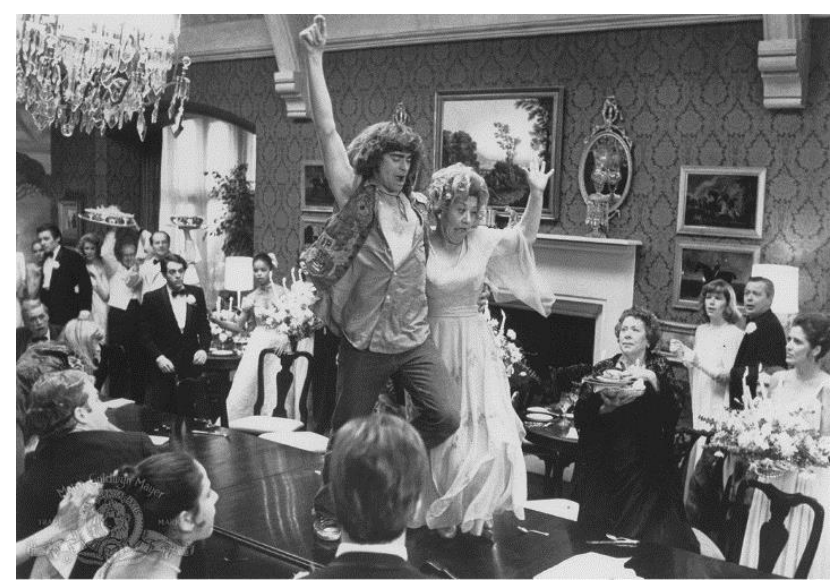

Fonte: https://ia.media-

imdb.com/images/M/MV5BMTg0OTY3ODc5OF5BMI5BanB

Outro momento se destaca em uma cena de alucinação ou sonho, com figurinos fantasiosos e diáfanos, bem próprios dos sonhos e das alucinações produzidas pelo uso de drogas, características da época. (Figura 10) 
Figura 10: Figurino da cena de alucinação/sonho.

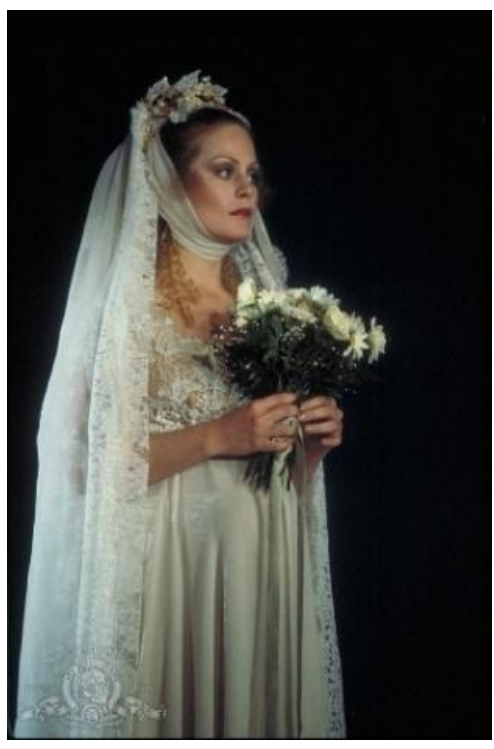

Fonte: https://images-na.ssl-imagesamazon.com/images/M/MV5BMjI2NjYzMzYzOF5BMI5Ban BnXkFtZTcwNTc4MjkzNA@@._V1_SY1000_CR0,0,666,1 000_AL_.jpg

Apesar de o filme Hair não ter obtido tanto êxito quanto o musical em termos de público e crítica, sua influência na moda foi bastante considerável, pois foi responsável por um resgate dentro da moda de uma tendência então desatualizada, a da cultura hippie, que hoje faz parte da memória coletiva da estética dos anos de 1970.

O filme "Os Embalos de Sábado à Noite", dirigido por John Badham (1977), conta a história de um jovem descendente de imigrantes italianos, vivendo no subúrbio de Nova York, que encontra na dança das discotecas sua alegria, tornando-se o "rei das discotecas". Aproveitando a febre das discotecas e uma trilha sonora sem precedentes do grupo já conhecido, Bee Gees, o filme foi um dos maiores sucessos do gênero em todos os tempos.

A música e as cenas de dança fazem parte do enredo, construído em torno de um concurso de dança e romance entre os parceiros. O filme também aborda temas inerentes à juventude da época como liberdade sexual, drogas e dança, e a esta temática deve-se creditar seu sucesso. 
O figurino contemporâneo, assinado por Patrizia von Brandenstein (1943-), seguia os padrões de vestimenta dos jovens de classe média baixa dos Estados Unidos na época e serviu para difundir pelo mundo o estilo "disco", consistindo em uma novidade que o figurino masculino fizesse mais sucesso que o feminino. Neste caso, o terno claro usado com camisa escura e botas, usado pelo personagem de John Travolta, Tony Maneiro, foi copiado exaustivamente nas pistas de dança por muitos anos seguintes e, além disso, o filme mostrava um homem extremamente vaidoso sem questionar sua masculinidade. A lendária cena inicial do filme mostra o personagem andando em um ritmo cadenciado pelas ruas de Nova York, usando calças jeans, camisa vermelha, jaqueta de couro e botas, também um ícone da moda dos anos 1970. (Figuras 11 e 12)

Figura 11: Cena inicial do filme "Embalos de Sábado à Noite".

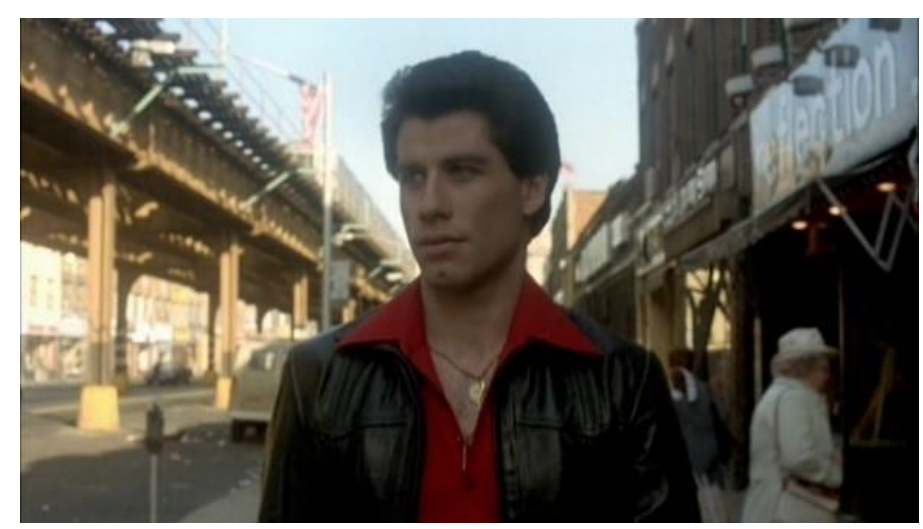

Fonte: http://br.web.img3.acsta.net/r_1920_1080/pictures /210/417/21041777_2013091916041069.jpg 
Figura 12: O figurino clássico das pistas de dança dos anos 1970.

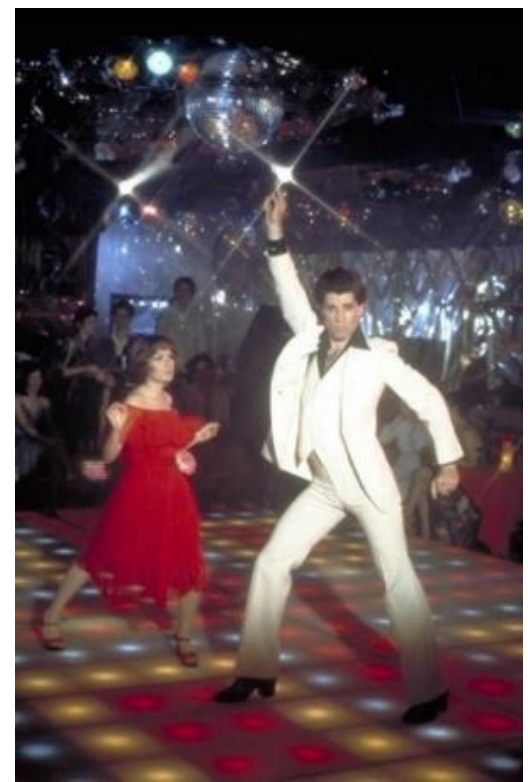

Fonte: http://br.web.img3.acsta.net/r_1920_1080/ pictures/17/05/17/15/28/142087.jpg

A análise dos filmes escolhidos mostra, de uma forma exemplificada, como o cinema pode fazer parte da pesquisa histórica dos figurinos como também de outros aspectos característicos de uma época, como cenografia, hábitos e costumes de um grupo social, mesmo que através do ponto de vista dos criadores do projeto fílmico. O contexto histórico fica impregnado nas imagens e como disse Marc Ferro (1987), "quatorze minutos de um filme falam mais que duas horas de palestras ${ }^{\prime 3}$, sobre um filme documentário sobre o racismo nos estados unidos.

\section{CONSIDERAÇÕES FINAIS}

Em seus mais de cem anos de existência, a" Sétima Arte" como o cinema é considerado, pode proporcionar infinitas interpretações. Vários aspectos podem ser avaliados e analisados de forma independente ou em conjunto,

\footnotetext{
${ }^{3}$ Conferência realizada na Faculdade de Ciências e Letras de Assis, UNESP, em 27 de agosto de 1987. Youtube, acesso em 02 jun. 2018.
} 
cenografia, linguagem, fotografia, etc. Analisar o figurino de filmes musicais com intuito de buscar fontes históricas de pesquisa e sua relação com a moda é uma das muitas possibilidades que o design proporciona dentro do universo fílmico.

Filmes como Amor, Sublime Amor, Hair e Embalos de Sábado à Noite, são exemplos de produções cinematográficas musicais, que marcaram época através da abordagem da temática dos conflitos da juventude, conjuntamente com trilhas sonoras inesquecíveis. Estes filmes tornaram-se clássicos da cinematografia e são verdadeiros documentos de sua época. A análise de seus figurinos através do design e a influência exercida por eles na moda, proporciona um conhecimento das sociedades que cada filme representa. A cidade de Nova York foi o cenário principal onde as tramas dos três filmes escolhidos acontecem. Em Amor, Sublime Amor o figurino contemporâneo caracteriza as diferenças entre as duas sociedades retratadas. Os interesses conflitantes existentes entre os jovens estadunidenses e a nova geração de imigrantes porto-riquenhos foi mostrado através da escolha da paleta de cores das roupas de cada grupo. Em Hair, a reconstituição do figurino "hippie", influenciou a moda da época e as diferenças dos trajes deixou claro, dentro da trama do enredo, o evidente distanciamento existente entre os personagens pertencentes a classes sociais distintas. E, em Os Embalos de Sábado à Noite, o figurino contemporâneo marcou sua época se transformando em um ícone de moda do final dos anos 1970 juntamente com uma trilha sonora consagrada nas paradas de sucessos da época.

Ao fornecer uma maneira de se classificar os figurinos dos filmes, este texto pretende servir de catalisador para futuras explorações dentro da temática da interação do cinema e da moda e que através da interpretação de 
elementos dos figurinos o cinema possa, também, servir como importante fonte de pesquisa histórica no campo da moda.

\section{REFERÊNCIAS}

BATTISTI, Francisleth Pereira. Moda e figurino: unilateralidade. Publicação $1^{\circ}$ Encontro Paranaense de Moda, Design e Negócios. Maringá, 2009.

BETTON, Gerard. A Estética do Cinema. São Paulo: Martins Fontes, 1987.

CABRAL, Alexandra; FIGUEIREDO, Carlos Manuel. o Figurino na Construção das Personagens e do Drama da Ficção Cinematográfica. CIAUD - Centro de Investigação em Arquitectura, Urbanismo e Design Faculdade de Arquitectura da Universidade Técnica de Lisboa, $8^{\circ}$ SOPCOM Comunicação Global, Cultura e Tecnologia, 2016.

CARPINTEIRA, Yolanda Maria Garcia. A Intervenção do Designer de Produção na Peça Cinematográfica. Dissertação para obtenção do grau de mestre em design de comunicação. Faculdade de Arquitetura, Universidade Técnica de Lisboa, 2011.

CINEMA, Adoro. Photo Gallery. Um Corpo que Cai: Foto James Stewart, Kim Novak. Disponível em: http://www.adorocinema.com/filmes/filme-

980/fotos/detalhe/?cmediafile $=18886613$. Acesso em : 20 de junho de 2017.

COSTA, Francisco Araújo da. O figurino como elemento essencial da narrativa. Sessões do Imaginário. Porto Alegre, no 8, ago, FAMECOS/PUCRS, 2002.

DE LA HAYE, Amy. Fashion Sourcebook: A Visual Reference to Twentieth Century Fashion. London: Macdonald \& Co Ltda, 1988.

FERRO, Marc. Cinema e História. Rio de Janeiro: Paz e Terra, 1992.

IMDB, Internet Movie Database. Photo Gallery: Hair (1979). Disponível em: http://www.imdb.com/title/tt0079261/mediaviewer/rm3728 246016. Acesso em 20 de junho de 2017. 
KORNIS, Mônica Almeida. História e Cinema: um debate metodológico. Estudos Históricos, Rio de Janeiro, vol. 5, n. 10, 1992.

LIPOVETSKY, Gilles; SERROY, Jean. A Estetização do Mundo, Viver na Era do Capitalismo Artista. São Paulo: Companhia das Letras, 2015.

SOUZA, Christine Veras. O Show Deve Continuar: o gênero musical no cinema. Dissertação de mestrado, Escola de Belas Artes, UFMG, BH, 2005

SOUZA, Amanda; et al. A Retomada do Gênero Musical. São Carlos, SP, 2011.

\section{FILMOGRAFIA}

AMOR Sublime Amor (West Side Story). Direção: Robert Wise; Jerome Robbins. EUA, 1961.

EMBALOS de Sábado à Noite, OS (Saturday Night Fever). Direção: Direção: John Badham. EUA, 1977.

HAIR. Direção: Milos Forman. EUA, 1979 